\title{
The role of self-determination in informal and formal science learning contexts
}

\author{
Hannu Salmi ${ }^{1} \cdot$ Helena Thuneberg ${ }^{1}$
}

Received: 30 March 2017 / Accepted: 13 March 2018 / Published online: 19 March 2018

(C) The Author(s) 2018

\begin{abstract}
The goal of this research was to explore cognitive, self-determined learning and autonomous motivational effects in the context of a mobile science exhibition $(N=256)$ in Finland. The pupils were sixth-graders with an average age of 12 years 6 months. Autonomy experience, as measured by the Relative Autonomy Index (RAI), had an effect on how the pupils liked learning science both at school and in a science centre context. The more autonomous that students feel, the more likely it is that they have intrinsic motivation in learning science. The RAI also predicted momentary situational motivation. The most important enhancer of situation motivation was liking science learning at school, but this was true only among boys; nevertheless, in general, girls were somewhat more motivated by the science exhibition than boys. There was no gap between boys and girls in postknowledge testing, suggesting that girls benefitted more from the science centre learning experience than boys. Although gender differences in the knowledge tests leveled, students having higher reasoning ability, measured by Raven, gained more from the exhibition than the others. Post-knowledge was explained most by pre-knowledge, but the overall substantial learning results were enhanced directly and indirectly by the motivational factors. The practical implication for the science centres is to offer both teachers and pupils learning materials to be used before and after the visits.
\end{abstract}

Keywords Informal learning · Interest - Motivation · Open learning environment · Science centre pedagogy $\cdot$ Self-determination

\section{Introduction}

There is evidence that informal environments could have strong effects on learning (Bitgood 1988). Especially in regard to informal science centre education, studies have

Hannu Salmi

hannu.salmi@helsinki.fi

1 University of Helsinki, P.O. Box 9, 00014 Helsinki, Finland 
mainly concentrated on its effects on motivation (Holmes 2011; Osborne and Dillon 2008; Salmi 1993, 2003, 2012; Tan and Subramaniam 2003; Vainikainen et al. 2015; Vennix et al. 2017). However, in our study, the goal was to analyse motivation as a multifaceted phenomenon by simultaneously taking into consideration the more stable self-determined autonomous motivation, the situation motivation and the interest in science in different learning contexts. The aim was to show the complex net of effects in the informal science learning environment. In the rather comprehensive model the relative role of different motivational effects, also in relation to cognition, was explored not only to support development of the theory, but also to help in planning even more effective and interesting informal learning environments. The relevance of this study, thus, was also to provide pragmatic solutions for the long-running challenges of science centres and museums. Are these institutes capable of orienting and enhancing the momentary, strong situational interest and motivation into a long-lasting intrinsic motivation (Rennie 2014; Salmi 1993, 2003, 2012)?

In many cases, it has been found that gender plays an important role, and that the attitudes of girls from early on already tend to become more negative towards science than do the attitudes of boys (Farenga and Joyce 1999; Hong 2010, 2013). Moreover, science interests differentiate according to gender as well as to age (Jidesjö 2008, 2012). However, the science centre learning situation has been shown to enhance learning in addition to reducing the knowledge achievement gap between girls and boys or different achievers (Ainley et al. 2002a; Salmi et al. 2016; Zoldasova and Prokop 2006).

The context of this study was informal education (science centre pedagogy), which took place in the mobile science exhibition. The objective was to identify students and student groups who gain the greatest benefit, or those who cannot obtain 'cost-effective' learning results through pedagogy, from this type of informal science education. In particular, we were interested in identifying similarities and differences in motivational and learning factors between the boys and girls because several earlier studies indicated gender equal results in informal learning environments compared with formal education (Doppelt 2004; Rennie 2014). This comparison is essential because, according research (Salmi et al. 2016), science centres also have turned out to encourage boys and girls towards unconventional educational aspirations and to gain positive cognitive and affective results (Thuneberg et al. 2017). In order to identify the role of motivational factors, it was necessary to control the role of cognition and reasoning, which was achieved by using a visual reasoning ability (Raven) test in this study.

These goals were challenging because conducting educational research even in the traditional closed classroom settings is often demanding because of the context. However, research in informal learning environments is still much more complicated because of the uncontrollable variables (Falk and Dierking 2002; Rennie 2014).

The theoretical framework for our study included motivational variables: autonomous motivation (Relative Autonomy Experience, RAI), situation motivation and learning context (interest in science learning in school and in science centres). The cognitive variables were visual reasoning (Raven) and science knowledge pre- and post-test. All of these variables were considered in relation to gender.

Next, we present theoretical points associated with informal science learning environments and, following that, we look at our motivational framework, Self-Determination Theory, situation motivation, interest in science learning in the two contexts and theoretical considerations of visual reasoning. 


\section{Informal science learning in open learning environments}

Since the 1960s, informal education has been clearly defined mainly by the UNESCO report Learning To Be (Faure et al. 1972) to mean that learning is taking place outside the formal education system. The role of informal learning is increasing with the growing impact of new technologies (Radu 2014), digitalisation and research results related to our everyday lives. Lifelong learning in modern societies needs new practical forms (Salmi et al. 2015), and thus, informal education has become a widely accepted and integrated part of school systems during the last three decades (Fenichel and Schweingruber 2010; Salmi 1993; Salmi et al. 2017). Out-of-school education forms a pedagogical link between formal education and informal learning (Braund and Reiss 2007; Rennie et al. 2003) because it is a term included in school legislation in several countries (Rennie 2014). It refers to using informal education sources for formal education.

Science centre pedagogy, originally pure informal learning, is nowadays often applied as a form of out-of-school education (Salmi 2012). According to meta-studies (Rennie 2014) and research literature, science centre and museum education has strong motivational effects (Braund and Reiss 2007; Rennie et al. 2003; Salmi 2012). Also, the effect on knowledge learning has proven to be meaningful (Rennie 2014; Salmi et al. 2016), and there is clear evidence that science centre pedagogy advances attitudes (Osborne and Dillon 2008; Thuneberg et al. 2017) and career choices (Tan and Subramaniam 2003).

Frank Oppenheimer (1968) has been noted as the creator of science centre pedagogy (Hein 1990). His criticism of the passive pedagogy of science education derives implicitly from Dewey's ideas (1938) expressed in his thesis of 'learning by doing'. The same approach can be seen in contemporary developments in science centre pedagogy (Braund and Reiss 2004; Salmi 1993, 2003; Salmi et al. 2017): The famous 'hands-on' principle articulated by Oppenheimer is a cornerstone of the interaction in modern science centres. What Dewey and modern science centre pedagogy share is the emphasis on motivation, free will and the learner's own activity which is stimulated by the context and is not forced. These features enhance fulfilment of the autonomy need and engagement in exploration and learning (Hagger et al. 2016). Self-determined learning clearly forms a firm theoretical basis for research in the context of this present study.

\section{Motivation through the lens of self-determined learning}

A learner's autonomy and personal agency are central for self-determined learning according to Self-Determination Theory (SDT) (Kaplan 2008; Reeve et al. 2008; Zimmerman and Schunk 2007). Furthermore, when motivation initiates a behaviour, the behaviour becomes guided by self-regulation. The perceived locus of causality (i.e. whom a student perceives to be the origin of action) affects how self-determined the behaviour is. Using Deci and Ryan's (2007) definition, this means how interesting, important and vitalising behaviour is, and how autonomously behaviour is regulated.

SDT suggests a self-determination continuum from less autonomous motivation towards a more autonomous, self-determined direction (Ryan and Deci 2002). At one extreme of the continuum, the pupils are amotivated, which means that they are not at all motivated or that their motivation is very low. This corresponds to non-regulation, which in practice means that they are passive in relation to their school work. External regulation indicates that children act because they want to avoid punishment or to gain rewards. Introjected 
regulation implies that students behave because of experiences of inner pressure (Ryan and Deci 2000a), which have been shown to be connected with anxiety in school (Grolnick and Ryan 1989). Identified regulation ${ }^{1}$ means that students are willing to engage in school tasks because school is important for them. It is connected both with enjoyment of school and proactive coping strategies (Grolnick and Ryan 1989). At the other extreme of the continuum is intrinsic regulation, in which the cause of behaviour is interest in the activity itself, curiosity or pure enjoyment. The grade of self-determination in the continuum, according to SDT, depends on fulfilment of basic psychological needs, autonomy, competence and relatedness. Those needs were not directly measured in the present study, but they are essential factors affecting the Relative Autonomy Experience (RAI) (explained in more detail in "Methods" section).

Experienced autonomy means choice and a possibility to control one's own actions, realise intentions and avoid undesired events. In autonomous behaviour, agency experience and being a source of origin is essential (Ryan and Connell 1989; Skinner and Edge 2002). Competence need is an innate need to master one's environment (Elliot et al. 2002; White 1959) and to experience self-efficacy and self-worth based on the skills needed in the learning situation (Deci and Ryan 2000). According to the SDT-theory (Ryan and Deci 2002), if success is experienced only based on luck or just as an organised win by others, it reduces self-determination and sense of competence. Relatedness need means need for relationships for which one feels accepted and liked, a sense of being with others, security and unity (Ryan and Deci 2002). Relatedness needs fulfilment is characterised by warmth of environment and a deprivation of the need by threat (Eccles and Wigfield 2002). Good social relationships have been shown to be significant predictors of motivation (Ryan and Deci 2000b). The psychological needs are intertwined in that, from one need's fulfilment, how the other two are being satisfied can be predicted (La Guardia et al. 2000).

The learning environment can either support or thwart fulfilment of the needs. The more the three psychological needs are satisfied in a school environment, the more a child is free mentally to engage in learning and in intrinsically interesting school tasks and the more he or she is willing to integrate with school goals. Accordingly, self-regulation is less external (Deci and Ryan 2000; Grolnick et al. 1991; Ryan and Deci 2002). Self-determined learning involves ways of engagement in learning activities such as school tasks, tests and homework (Deci et al. 1996). It relates to the selection of competing motives and volition (Corno 2004; Deci et al. 1996). Furthermore, it relates to coping in case of failure and to tolerance for ambivalence (Hautamäki et al. 2002). Thus, the better that the basic psychological needs are constantly fulfilled, the better are the consequences: more autonomous self-determined motivation, higher willingness to learn, deeper learning, higher grades, more creative outcomes and better self-esteem. These are considered crucial for future educational aspirations (Benita et al. 2014; Eccles and Wigfield 2002; Reeve 2002; Richardson et al. 2012; Ryan and Deci 2000a).

Support for autonomy has also been shown to enhance science learning attitudes. In a learner-centred 2-year science education project (Jalil et al. 2009), autonomy was emphasised by, for example, allowing students first to experiment on their own. Autonomy support led to intrinsic motivation and positive attitudes towards science. The deprivation

\footnotetext{
1 Integrated regulation between identified and intrinsic regulation is rarely found among pupils, which is why it is not included in the questionnaire measuring these types. The reason for the behaviour in integrated regulation is that it is experienced as an integral part of self, although it is still external (Deci and Ryan 2000; Ryan and Deci 2000a).
} 
of psychological needs, however, has been reported to lead to unfortunate consequences such as dropout (Eisenman 2007; Hardre and Reeve 2003) and, in extreme cases, criminality (Quinn et al. 2005; Winters 1997) or even suicidal behaviour (Bender and Wall 1994; Svetaz et al. 2000).

\section{Situation motivation}

Situation motivation is a characteristic feature of extrinsic motivation. Most often it is related to a new place with a stimulating environment (Braund and Reiss 2004; Zoldasova and Prokop 2006), which might also contain elements of intrinsic motivation through curiosity (Salmi et al. 2016). Social relations, external factors, emotions, humour and temporary actions are typical conditions for it. Typical features for situation motivation are: (1) short-lasting motivation; (2) easily disturbed learning; and (3) orientation of learning to irrelevant subjects (McClelland 1951; Salmi 2003). Situation motivation has its origin deep in the evolution of homo sapiens as is shown in the early discoveries of eustress (Selye 1957). Active behaviour through all five senses is also a feature of situation motivation.

\section{Interest in science learning in two contexts}

In our theoretical model, there are two learning contexts, school and science centre, in which the pupils rate how interesting they find science learning in each context. Interest has been found to be an important affective motivational factor which supports focusing attention to tasks, increases cognitive functioning and enhances learning (Renninger and Hidi 2011). Thus, it was justified to include it in our research design.

Boys and girls have shown to differ in relation to interest. Boys' learning tends to be more dependent on interest than that of girls. When interested, boys perform better, but girls are more persistent learners than boys when they are uninterested (Ainley et al. 2002b; Schiefele et al. 1992; Vainikainen et al. 2015).

\section{Visual reasoning}

Thinking skills, or the ways in which people reason to solve problems, are considered essential to effective learning (Adey et al. 2007; Demetriou et al. 2011). According to Fisher (2005), they are habits of intelligent behaviour which can be learned by practice. The more that reasoning skills develop, the more that pupils can gain from learning and life (Adey and Shayer 2002). In our conceptual model, we included visual reasoning and used it as a control variable. Reasoning and thinking skills are essential in learning science because they relate to metacognitive awareness and epistemic knowledge (Harris 2002; Michalsky et al. 2009), which free pupils from being bound only to the rote learning of scientific facts and support them in taking a critical stance and weighing the knowledge that they learn (Duschl et al. 2007; National Research Council 2007). Most of the cognitive tests demand both reading and writing skills. However, the learning outputs are knowledge and skills (Greenfield 2009), which should be the focus of research in both school and informal learning environments (Alberts 2009; Rennie 2014).

\section{Research questions}

On the basis of the learning environment theory, the research questions were as follows: 
1. To what extent do the motivational variables predict students' knowledge learning?

2. What kind of a role does self-determined motivation play in situational motivation and science interest at school and at the science centre?

Based on the literature reviewed, we hypothesised that autonomy experience would enhance science learning interest both at school and at the science centre, situation motivation and knowledge. Because the science interests of boys and girls have shown to differ, we also examined the role of gender. Based on the Raven test theory and previous studies, visual reasoning was hypothesised to be similar for boys and girls.

\section{Methods}

\section{Context of the study: the mobile science exhibition}

The mobile science exhibition brought learning experiences to schools throughout Finland, and especially to areas without easy access to existing science centres. These mobile science exhibitions presented an interactive science experience accompanied by several carefully selected hands-on exhibits. The target group was comprehensive school classes with students from the age of $11-13$ years old $(M=12.59$, SD $=0.53)$. 'Everyday science' was the starting point for planning content for the demonstration and exhibits. The idea was to find links between scientific concepts (e.g. friction) and the phenomena of pupils' everyday lives (e.g. skiing and skating).

The content was planned to support science education in relation to the school curriculum, especially physics, chemistry and biology. Generating motivation for learning was one of the main goals of the project. The exhibition was visited by 25,000 pupils (the age cohort in Finland is around 57,000). Following 2 years of development work, the exhibition has been refined to a great degree.

The touring mobile exhibition (approximately $200 \mathrm{~m}^{2}$ ) was set up in the lobby, hall or gymnastics hall of the school. The exhibition consisted of interactive science, technology and engineering objects. The objects were found, for example, in the classic Exploratorium Cookbook by Oppenheimer (1968) and Hein (1990). These eight exhibits and two guided demonstrations were planned for 11-13-year-olds. The main idea was to give pupils an opportunity to explore hands-on exhibits through their own motivation. Voluntary movement in the exhibition according to one's own plan was the main pedagogical approach. This gave pupils an opportunity to make observations, rather than simply teaching them single facts. However, the exhibitions had clear objectives and goals, which were underlining the role of attractiveness and attitudes. Thus, it formed a fruitful foundation for self-determination and motivation research (Salmi et al. 2016).

The pupils visited the exhibition and participated in experimental learning sessions in order to acquire knowledge and skills that would support the science curriculum learning goals of their school year. The open learning environment also encouraged autonomous inquiry, and different interpretations of the phenomena were emphasised. 
Table 1 Design of the study

\begin{tabular}{lll}
\hline Variables assessed prior to visit & One-month activity & Variables assessed after visit \\
\hline Pretest & Science exhibition visit & Post-test \\
Motivation (Deci and Ryan) & & Situation motivation \\
Knowledge test & & Knowledge test \\
School learning context & & Science centre learning context \\
Background variable: gender & \\
\hline
\end{tabular}

\section{Design of the study}

The educational activities provided by the mobile exhibition 'Science Circus' were repeated each time according to the same script, timetable and well-known measures (Table 1).

\section{Sample}

The sample consisted of 256 pupils (56\% boys) from 16 classes, aged 12-13 years. The participants were drawn from all schools and classes that attended the touring mobile exhibition.

Because the participants were children, ethical factors were thoroughly considered. This included obtaining written consent from the parents, carefully explaining the study's goal to the children, and assuring them that their answers would not affect their school grades.

\section{Tests and measurements}

\section{Deci-Ryan test: self-determined motivation}

The Deci-Ryan Intrinsic Motivation (SRQ-A: Self-Regulation Quality-Academic) test has 32 standardised items. Each item has four options $(1=$ not at all true, $2=$ not nearly true, $3=$ somewhat true, $4=$ totally true). A sample question is: 'Why do you want to answer hard questions during lessons?' The questions and statements were formulated based on the basis that the summative variables are equal to the self-determination continuum and according to the self-regulation degrees of external, introjected, identified and intrinsic. The weighted relation of the individual summative variables can be used to form an overall autonomy index: the RAI-Relative Autonomy Index. It is formed based on the formula: $2 \times$ intrinsic +identified - introjected $-2 \times$ external (Ryan and Connell 1989). The RAI describes the overall autonomy level experienced by the pupil. A negative-signed index indicates non-self-determination, and a positive-signed index indicates self-determination (i.e. autonomy).

The Deci-Ryan test was administrated as a pretest because, theoretically, there should be no major changes in the overall motivation related to whole personality after a 1-day intervention. Thus, in the modelling RAI was used as the control variable.

The reliability of external was $\alpha=0.87$ (9 items), of introjected was $\alpha=0.85$ ( 9 items), of identified was $\alpha=0.86$ (7 items) and of intrinsic was $\alpha=0.87$ (7 items). 


\section{Semantic differential: the learning context}

The semantic differential is a traditional method (Hofstein and Rosenfeld 1996) that uses a set of bipolar terms from which respondents can select and express their alternatives. Semantic differential questionnaire often utilises a continuum type of scale (1-5 in this study). The method is best used in situations in which the same content or nearly the same topic is taught or learned but in a different context or environment.

The semantic differential test consisted of 14 items. Students give their own impression about typical concept pairs representing a continuum ('Learning chemistry at the school/at the exhibition is: easy-difficult' or 'I think that science learning at the school/ at the exhibition is: important-useless'). In the first phase, before the exhibition, students' opinions and attitudes were measured concerning learning science, chemistry and physics in the school classroom environment. In the second phase, after the exhibition, the measured items were related to the science exhibition context.

The reliability of the first phase test was $\alpha=0.87$ (14 items) and of the second phase was $\alpha=0.90$ (14 items).

\section{Situation motivation test}

Situation motivation is a characteristic feature and subgroup of extrinsic motivation. Most often it grows from a new situation. Temporary and external factors, as well as social relations and entertainment, are significant factors. Typical of situation motivation are: (1) short-lasting motivation; (2) easily disturbed learning; and (3) orientation of learning to irrelevant subjects (Atkinson 1964; McClelland 1951; Salmi 1993, 2003; Thuneberg et al. 2017; Vainikainen et al. 2015).

Situation motivation was measured with 13 Likert scale items (totally agree-totally disagree). The items were constructed and made instrumental in relation to extrinsic elements like 'edutainment'. A sample item is 'I wish I would have had a chance to stay longer at the exhibition'. The questionnaire was only administrated as a post-test. The reliability of the test was $\alpha=0.86$ ( 13 items).

\section{Raven standard progressive matrices: visual reasoning ability}

According to the test theory (Raven et al. 2000, 2003), the main elements in common cognitive ability are the capacity to learn and the capacity to embrace and remember the knowledge once learned. In this study, reasoning ability was measured and evaluated by the Raven Standard Progressive Matrices (Raven et al. 2000). This test has been utilised very widely in both practice and theoretical research. The cumulative amount of data in different age groups, schools and socio-economic cultures has established the Raven test to be valid. In addition, it does not give any advantage to male or female students. The Raven test was only administered as a pretest and as the control variable in the modelling because of its rather stable nature.

In each test item, the subject is asked to identify the missing element that completes a pattern. The test contains 60 task items divided into five sets. Each group contains 12 different tasks. For each of the tasks, the student fills in the figure. Every set yields 12 scores, with the total being 60 . The students also tended to like this visual test more 
than traditional writing questionnaires. The reliability of the Raven test was $\alpha=0.85$ (60 items).

\section{Pre- and post-knowledge tests}

The knowledge test consisted of 59 items related to the content areas of the science exhibition. Example statements are 'Different objects are placed on a horizontal plane. When the plane is tilted, it is always the lightest objects that start gliding first' and 'An adult human being has approximately 1.5 litres of blood is his/her body'. The test was presented to pupils approximately 1 month before the science centre visit and repeated as a posttest 7-11 days after the visit. Pupils were given with short written stimuli followed by one to four statements. The pupils' task was to judge whether the statements were correct or incorrect. They also had a 'don't know' option (Muijtjens et al. 1999). Only the sum of correct answers was used in the present study.

The items contained varying age-appropriate types of content and context:

(a) Certain items measured content already taught to students according to the curriculum during the early classes of the school (aged 7-10 years).

(b) Some items measured the topics taught during the previous term, present term and recent weeks from actual lesson and textbook topics.

(c) Some items were created to measure the content 'coming soon' to be taught during the next months and curriculum periods;

(d) A small number of items were clearly testing more-demanding content, which is typical only after some years in the secondary or even upper-secondary school.

(e) A few items evaluated content that does not belong directly to the official school curriculum or which is a fragmentary part of extra-curriculum activities.

The last definition above represents organically the spirit of informal learning represented also by the mobile science demonstrations and exhibition. The structure of the test items deliberately articulated the principle of informal learning. The content of the exhibition did contain knowledge, information and phenomena which students neither knew nor had any opportunity to learn before. The knowledge test was developed and piloted with a sample $(n=76)$ half a year before the actual data collection started. The reliability of the pretest was $\alpha=0.84$ (59 items) and of the post-test was $\alpha=0.88$ (59 items).

\section{Analysis methods}

The means and standard deviations of the variables and statistical significance of changes (one-way analysis of variance) were studied first. Because the aim was to explore the effects of motivation on learning, whether any learning happened between the pre- and post-test had to be analysed. The general linear model (GLM) repeated measures option and Wilks' lambda were used to test the overall significance of the change between the preand post-knowledge tests; this change indicated learning. The interaction effect of time and gender was analysed by using gender as a between-subjects factor. The effect size measure was partial $\eta^{2}$ (interpretation $\eta^{2}>0.01$ small, >0.06 medium, >0.14 large; Cohen 1988; Miles and Shevlin 2001).

We used Structural Equation path modelling (AMOS 22) to reveal how well the observed data fitted the theoretical model. Before the modelling, bivariate correlations 


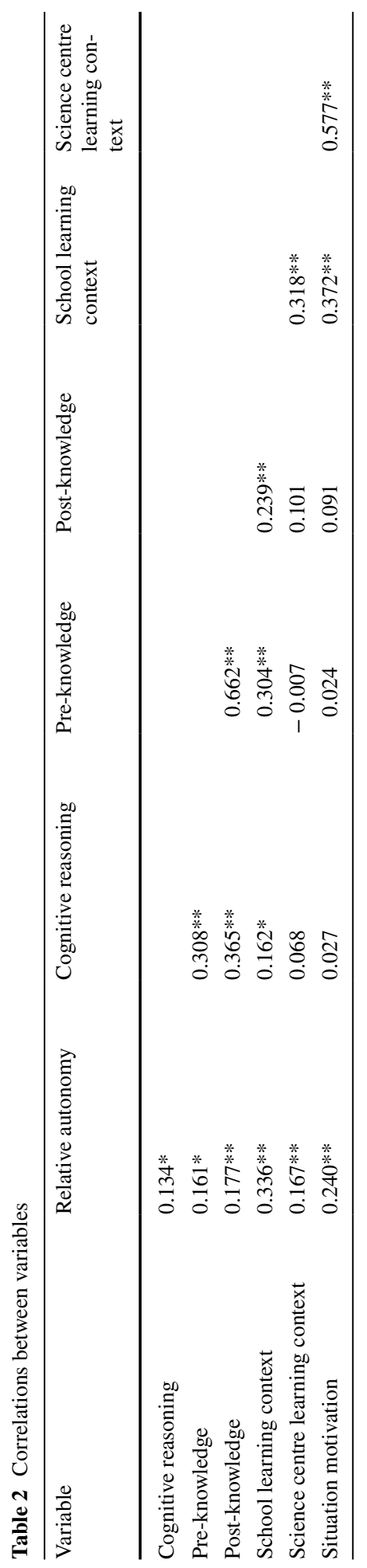


between the variables were studied. The modelling was performed using the parametric bootstrapping method and the Bollen and Stine (1992) option, which in AMOS provides indirect effects and their corrected significance. The correlations of the variables were studied before the modelling (see Table 2). Gender, Raven and RAI were used as covariates to control their effects on the pre- and post-knowledge tests, on situation motivation, on the school learning context and on the science centre learning context. In addition to RAI, the role of the sum variables of the self-determination continuum (external, introjected, identified and intrinsic) was tested in the phase that sought to get a supplementary perspective for the path modelling.

The goodness-of-fit evaluation of the models was based on a $\chi^{2}$ test and NFI, CFI, TLI, IFI (good fit $>0.90$, or better fit $>0.95$ ) and RMSEA (reasonable fit $<0.08$, good fit $<0.05$ ) (Byrne 2010). The index of explained variance was $R^{2}$, which can be interpreted as the total explanation percentage of the predictive variables on the variable of concern. Standardised $\beta$ coefficients were indicators of the effects of the predictors. The moderation effect of gender was tested by the $\chi^{2}$ tests' difference between the unconstrained and fully constrained models. Pairwise comparisons of the regression weights (paths) between the models were analysed by the $z$ test.

\section{Missing values}

There were only a few missing values. Values for the science centre learning context and situation motivation were missing in two cases of learning context. Those four values were substituted by the average of those variables when the significance of the indirect effects was tested because the bootstrapping method in AMOS requires a complete matrix.

\section{Results}

\section{Statistical descriptives}

The means, standard deviations and significant differences are shown in Table 3. There is a slight indication that, based on RAI, girls were more autonomous than boys $(p=0.052)$. Girls experienced themselves as being relatively autonomous because RAI was positive, but the boys experienced themselves as being non-autonomous based on the negative RAI. Girls also were more motivated by situation than the boys $(p<0.05)$. In turn, boys, scored higher in the pre-knowledge test than the girls $(p<0.05)$.

\section{Change in knowledge between pre-and post-test}

The GLM repeated measures test showed that overall the change in knowledge was significant (Wilks' lambda $F(d f=1)=136.27, p<0.001$, partial $\left.\eta^{2}=0.34\right)$. When gender was used as the between-subjects factor, there was a significant interaction effect of gender and time [Wilks' lambda $F(d f=1)=9.03, p<0.01$, partial $\eta^{2}=0.03$ ], which means that the change was different for boys and girls. Because of the interaction effect, the situation was analysed in split groups. The change for boys was significant [Wilks' lambda $F(d f=1)=46.90$, $p<0.001$, partial $\left.\eta^{2}=0.25\right]$. The change for girls was significant, as well, but the effect was larger [Wilks' lambda $F(d f=1)=102.01, p<0.001$, partial $\eta^{2}=0.46$ ]. 
Table 3 Descriptive statistics for boys and girls

\begin{tabular}{|c|c|c|c|c|c|c|}
\hline Variable & Gender & $N$ & Mean & SD & Min & $\operatorname{Max}$ \\
\hline \multirow[t]{3}{*}{ Raven } & Boy & 144 & 36.674 & 7.612 & 4 & 53 \\
\hline & Girl & 121 & 38.215 & 5.710 & 21 & 51 \\
\hline & Total & 265 & 37.377 & 6.841 & 4 & 53 \\
\hline \multirow[t]{3}{*}{ RAI } & Boy & 144 & -0.399 & 1.966 & -4.190 & 6.952 \\
\hline & Girl & 121 & 0.069 & 1.912 & -3.524 & 6.111 \\
\hline & Total & 265 & -0.186 & 1.952 & -4.190 & 6.952 \\
\hline \multirow[t]{3}{*}{ PreKnow } & Boy* & 144 & 85.729 & 9.852 & 41 & 104 \\
\hline & Girl & 121 & 83.471 & 8.551 & 59 & 106 \\
\hline & Total & 265 & 84.698 & 9.332 & 41 & 106 \\
\hline \multirow[t]{3}{*}{ PostKnow } & Boy & 144 & 90.236 & 11.194 & 48 & 107 \\
\hline & Girl & 121 & 90.876 & 9.238 & 58 & 111 \\
\hline & Total & 265 & 90.528 & 10.333 & 48 & 111 \\
\hline \multirow[t]{3}{*}{ SchoolCont } & Boy & 144 & 47.465 & 9.727 & 16 & 68 \\
\hline & Girl & 121 & 46.669 & 7.695 & 24 & 70 \\
\hline & Total & 265 & 47.102 & 8.850 & 16 & 70 \\
\hline \multirow[t]{3}{*}{ CentreCont } & Boy & 144 & 51.257 & 13.025 & 1 & 70 \\
\hline & Girl & 121 & 53.562 & 10.660 & 1 & 70 \\
\hline & Total & 265 & 52.309 & 12.036 & 1 & 70 \\
\hline \multirow[t]{3}{*}{ SitMot } & Boy & 144 & 49.063 & 9.763 & 14 & 65 \\
\hline & Girl* & 119 & 51.697 & 6.475 & 27 & 65 \\
\hline & Total & 263 & 50.255 & 8.523 & 14 & 65 \\
\hline
\end{tabular}

$* p<0.05 ; * * p<0.01 ; * * * p<0.001$

\section{SEM path modelling}

The significance of the direct and indirect effects of the variables was obtained by SEM path modelling. We also tested alternative models by unravelling RAI to the summed variables external, introjected, identified and intrinsic in order to illuminate the nature of the RAI in a more versatile way. However, the main elaboration of the model was achieved by using RAI because the aim was to reveal the role of the overall experience of autonomy.

The final model consisting only of the significant effects fitted the data well $\left(\chi^{2}=20.146\right.$, $d f=14, p=0.126$; NFI $=0.955, \mathrm{IFI}=0.986, \mathrm{TLI}=0.961, \mathrm{CFI}=0.985$, RMSEA $=0.041)$. The final model is presented in Fig. 1.

The modelling results (1-6 below) show which variables directly and indirectly predicted learning and motivation:

1. Pre-knowledge was directly explained by Raven, gender, RAI and school learning context $\left(R^{2}=0.19\right)$. Being a boy (boy coded as 0 , girl as 1 ) predicted higher pre-knowledge test results.

2. Post-knowledge was directly predicted by Raven, pre-knowledge and science centre context $\left(R^{2}=0.48\right)$. It was, in addition, indirectly predicted by $\operatorname{Raven}(\beta=0.19, p<0.01)$ and by school learning context $(\beta=0.18, p<0.01)$. Thus, the higher that visual ability scores were for pupils, the more they liked science learning, the higher were their knowledge test scores after the exhibition and vice versa. But of course, the more that 


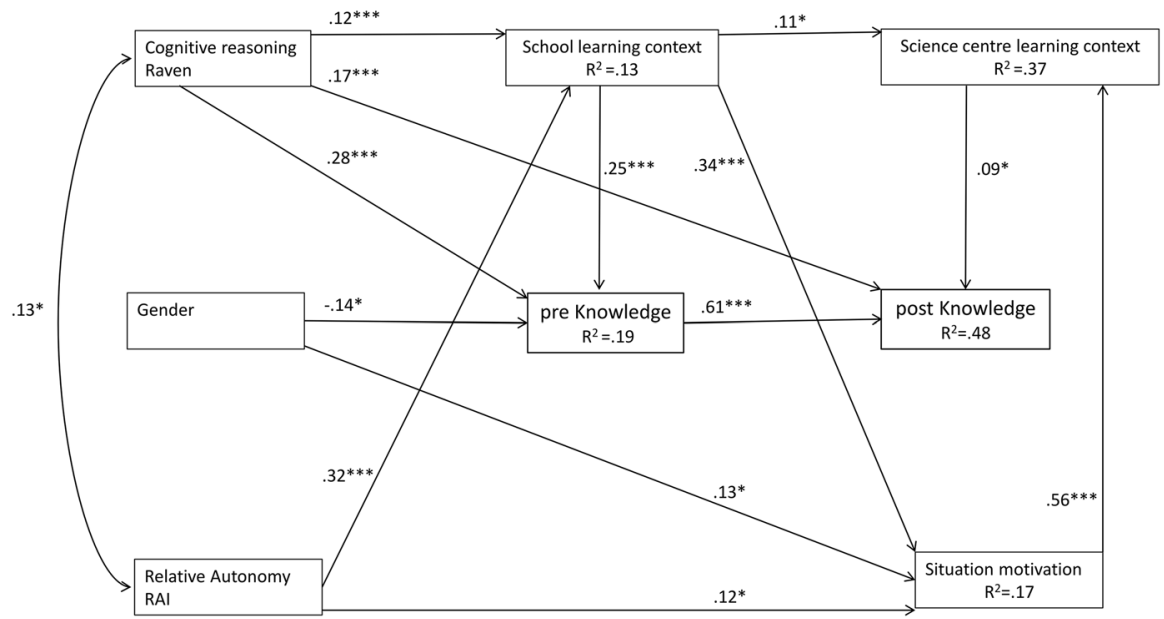

Fig. 1 The final path model $(* p<0.05 ; * * p<0.01 ; * * * p<0.001)$

the pupils knew beforehand, the more that they knew also after, and prior knowledge was the strongest explainer of the variables.

3. Situation motivation was directly explained by RAI, gender and school context $\left(R^{2}=0.17\right)$. Girls were more motivated by the situation than the boys. In addition, RAI had an indirect effect on situation motivation $(\beta=0.11, p<0.01)$. (Trivial significant indirect effects $(\beta<0.10)$ are not mentioned.) In other words, the more autonomous that the pupils felt, and the more that they liked science learning at school, the more motivation was aroused in the exhibition.

4. Instead of the RAI, the model was also tested by using the individual variables of the sum of the Self-Determination continuum. The finding was that introjected and identified motivation had no significant role on situation motivation, but external motivation $(\beta=0.13, p<00.05)$ and especially intrinsic motivation $(\beta=0.29, p<0.001)$ did. Thus, the pupils became more excited about the exhibition, the more that they generally liked to engage in the tasks. Situation motivation was somewhat aroused also because of external reasons, and not because they were genuinely interested in the exhibition content.

5. School learning context was directly explained by Raven and RAI $\left(R^{2}=0.13\right)$, and therefore visual reasoning and autonomy experience enhanced science learning interest in school.

6. Science centre learning context was directly explained by school context and situation motivation $\left(R^{2}=0.37\right)$. In addition, it was indirectly explained by $\operatorname{RAI}(\beta=0.15, p<0.01)$ and school learning context $(\beta=0.18, p<0.01)$. This indicates that interest in science learning at school also enhanced interest in the exhibition. In addition, motivation also influenced it.

The single items, indeed, gave some evidence. However, the results above (1-6) indicate that the chosen variables with their complex connections, indeed, widen our perspective on open learning environments.

The moderation effect of gender was tested to reveal whether the same model would fit both boys and girls. The models for boys and girls were invariant and therefore did not 
differ from each other. The difference between the unconstrained and fully constrained model was $\chi^{2}$ difference $=13.962, d f=11, p=0.235$. However, one path was different. The path from school learning context to situation motivation was nonsignificant in the girls' group $(p=0.055)$ but highly significant in the boys' group $(p<0.001),(\mathrm{z}=-4.76$, $p<0.01)$. In other words, whether or not girls like learning science at school was not important for arousal of motivation in the exhibition- but for boys it was.

\section{Discussion and conclusions}

Overall, this study revealed several encouraging trends and opportunities for the informal learning environment and out-of-school education in science exhibition settings. Bridging the gap between formal education and informal learning is clearly one of the future trends in pedagogy. However, no pedagogy can be an educational panacea (Salmi et al. 2017).

The first research question based on the learning environments literature involved the dilemma of the extent to which motivational variables predict students' knowledge learning. The empirical results gave clear evidence of the central role of the autonomy experience and intrinsic motivation of the learners as key indicators for knowledge learning.

The second main research question involved more-detailed information about what kind of a role self-determined motivation plays in situational motivation and in science interest at school and at the science centre. As an answer to this question, the path model in Fig. 1 shows the complex but clear connections and relationships that underline the role of selfdetermination as a catalyst for situation motivation and interest in science.

Our two main results support the results of two recent meta-studies (Andre et al. 2017; Rennie 2014) but also provide new information in relation to contemporary studies (Vennix et al. 2017) related to museums and science centres as informal open learning environments.

\section{Self-determination's important role in learning environment}

Self-determination has an important role in learning regardless of whether the context is formal or informal (Deci et al. 1996; Ryan and Deci 2002). Our results show that autonomy experience, measured by the Relative Autonomy Index (RAI), was an important part of the science exhibition learning environment. Because the index was positive, we can conclude that overall pupils' behaviour was self-determined. Autonomy experience had an effect on how pupils liked learning science both at school and in the science centre context. The first effect was of moderate size but, after it had been controlled, there was still an effect in the exhibition, although it was smaller and indirect. The effect implies that more autonomous pupils felt that, in their learning environment, the more that they liked engagement in science (or vice versa), the less that they experienced self-determination and liked science at school and at the centre. These RAI results indicate that basic psychological needs, autonomy (pupils had possibility for choices), competence (pupils felt agency and efficacy) and relatedness (pupils experienced belonging and connectedness, participation) were fulfilled (see Eccles and Wigfield 2002; Elliot et al. 2002; Ryan and Deci 2002). The role of autonomy support in the science learning environment is interesting also because it is rarely analysed in learning environment research (Vennix et al. 2017).

These results correspond to previous research. According to Reeve and Halusic (2009), support for autonomy and applied control affects the quality of the learning environment. 
They list the following quality factors: having interesting things to do and possibilities to act; the kind of rules, restrictions and incentives; the goals; how decisions are justified; whether challenges are optimal; and, finally, the kind of feedback that is given and how the process and outcomes are assessed and evaluated. When these factors are optimal, they support and enrich pupils' inner resources and help to maintain intrinsic motivation (which is realised in the high positive RAI index). According to the theory (Ryan and Deci 2002), the opposite means that intrinsic motivation is threatened and that pupils might not be able to access and fully use their resources when needed (which is realised in the negative RAI index).

\section{The double-ended sword of situation motivation}

The RAI also predicted situation motivation; the more that autonomy was experienced, the more that situational motivation was awakened during the science centre visit. This is a common finding in the research literature (Salmi et al. 2016; Tan and Subramaniam 2003; Zoldasova and Prokop 2006), with situational effects being even stronger in some previous studies (Osborne and Dillon 2008; Vainikainen et al. 2015).

Interestingly, when the RAI was unravelled to the summed variables and used in the path model, the most self-determined style of motivation (intrinsic), clearly predicted situation motivation, but simultaneously the other non-autonomous extreme (external) also had an effect on it. Thus, we can conclude that situation motivation in a way was like a double-edged sword because there were two motivational threads leading to a rise of motivation in the science exhibition. The first edge, the more intrinsic one, was likely to support deeper engagement in exploring and learning and the other edge, the more external one, was related to rather more superficial fun-seeking. The latter might describe what has been referred to in the literature by the concept of edutainment (Corona et al. 2013), which includes exhibitions, education, tourism, computer games and augmented reality.

Situation motivation strongly affected the extent to which the informal science centre was experienced as a science learning environment. If situation motivation does not arise in the exhibition, the exhibition is far less likely to be perceived as a preferable learning environment. For those who like science at school, it might be not as critical because liking learning at school directly leads to liking it in the informal science learning environment as well. In this study, situation motivation and a positive attitude towards science learning at the centre had a small effect on the considerable knowledge gain obtained from the other direct and indirect sources. Thus, situation motivation and a positive experience of the science centre context might have not transferred into knowledge learning as much as expected.

Novelty is the key factor in stimulating interest and situation motivation in the science centres (Bitgood 1988; Braund and Reiss 2004; Salmi 2003; Vainikainen et al. 2015). The surprise of a new setting can be addressed by the so called 'sniff around corners' method (Balling and Falk 1981; Salmi 2012). It works also as a 'head-start' for the learning process. SDT (Reeve et al. 2008) underlines the fact that, during instruction in their learning environment, students must constantly perceive fulfilment of their psychological needs, autonomy, competence and relatedness — which also clearly are linked to intrinsic learning motivation. In this study, the most important enhancer of situation motivation was liking science learning at school-if a pupil had a positive attitude towards school science, this probably led to enthusiasm during the science centre visit. It is interesting that this was true only among boys. However, although the informal learning environment does not necessarily motivate pupils to work, the way in which they act in these informal learning settings 
depends on prior interest in science and their independent goal setting skills (Renninger 2000).

\section{Exhibition as a learning booster: but more among girls}

All students learned between the pre- and post-test. Interestingly, there was no boy-girl gap in post-knowledge. Therefore girls - maybe supported by their somewhat higher situation motivation-learned more and seemed to profit more from the science centre learning experience than the boys. Previously, the science centre learning situation itself has turned out to be generally interesting (Braund and Reiss 2004; Falk and Dierking 2002), which has been shown to reduce performance differences between girls and boys (Ainley et al. 2002a; Salmi et al. 2016; Thuneberg et al. 2017; Zoldasova and Prokop 2006; Vainikainen et al. 2015). On the other hand, the cognitive ability, measured by Raven, still had an effect on post-knowledge, suggesting that more-competent students gained more from the exhibition learning environment.

Despite girls being more motivated by situation, boys and girls did not significantly differ in their interest in science learning in either context. Moreover, the effects of interest in school or science centre context on learning did not differ based on the moderation analysis. This result deviated from a conclusions of Ainley et al. (2002b) and Schiefele et al. (1992), which indicated that boys' learning was more dependent on interest than that of girls.

\section{Motivation as a role-player in learning gains}

The Relative Autonomy Experience, situation motivation and liking science learning in both learning contexts were positively interconnected. These variables influenced pre- and post-knowledge. However, pre-knowledge was enhanced evenly by cognitive reasoning ability, and gender also had a minor effect. Because post-knowledge was explained largely by pre-knowledge, the more that pupils knew beforehand, the more that they also knew afterwards; however, this was not the whole explanation. Something, some phenomenon or motivation impetus existed and influenced the increase of knowledge from the exhibition. It is difficult or impossible to claim that the exhibition was a cause of the huge learning results (effect size of $34 \%$ by GLM), but surely it played a role. Roughly half of the post-knowledge variance was explained by the variables of the model, and they explained almost $40 \%$ of the variance in how pupils experienced the science centre as a learning context.

Most of the skills trained and taught in informal, open learning environments are definitively not text-based. The idea of an interactive, hands-on exhibition is to explore, test and repeat experiments according the scientific method. Therefore, 'there might be a mismatch between the structure of the knowledge and the structure of the print and language media traditionally used both to impart and test that knowledge' (Greenfield 2009, p. 71). Thus, paper-and-pencil tests alone cannot properly monitor knowledge and achievement in science.

Situation motivation has sometimes been considered even to be harmful for education and learning processes (McClelland 1951; Salmi 1993). Extrinsic motivation can lead to having only a superficial learning strategy, whereas situation motivation can create over-activity and restlessness (Salmi 2003; Zoldasova and Prokop 2006). However, active behaviour, making 
observations and gaining new input and stimuli by all of the senses are also features of situation motivation, as shown also in international comparative studies conducted in several countries (Salmi et al. 2016). The dilemma faced by the science exhibitions in promoting lasting interest and learning is whether they are capable of orientating the momentary, strong situation motivation into a long-lasting intrinsic motivation (Balling and Falk 1981; Falk and Dierking 2002; Vainikainen et al. 2015). Better learning results can be gained with a deep learning strategy based on learners' intrinsic motivation (Ryan and Deci 2002; Salmi 2003). Enhancing this is also one of the biggest challenges for open learning environments such as science centres.

\section{Limitations of the study and future research}

It is important to note two important limitations of our study. The bigger consideration relates to the study design and context. Although the aim was to find out the motivational and learning effects relating to the science exhibition, the research design was not a controlled experiment with an intervention and control group. Hence, the conclusion that observed effects happened because of the exhibition experience is not certain and only probable or most probable. Dealing with the first limitation in future research is an unrealistic challenge in the informal learning context because of increasing costs and the time-consuming nature of experimental/ control designs. More importantly, even though the results would be more valid and the effects of the exhibition more certain, having this kind of results would most likely not enhance the practical planning of the learning environment.

The other clear limitation relates to the analysis methods. The multilevel nature of the data consisting of several schools and classes was not addressed in this study, which is a limitation when interpreting the results. Ignoring possible clustering at different levels of the data can lead to over-estimation of significance (Snijders and Bosker 1999). This could be avoided in the future by using multilevel modelling (cf. MLwiN) and by applying a three-level model at the individual, class and school levels.

The added value of the study over previous ones is that, instead of merely concentrating on one kind of motivation, it refines the role of different motivational threads from the more stable autonomous motivation to short-term situation motivation and their relationship to interest in science learning in two types of learning environment, the school and the science centre. In addition, motivation was not studied separately but was controlled for by using cognitive variables, reasoning and knowledge learning, which show the relative position of cognition and motivation in a learning context.

As a future recommendation for new science centres and already-existing museums and exhibitions, the role of the pre- and post-learning materials is underlined. The exhibition experience becomes more cost-effective if both teachers and pupils receive enough information and knowledge about the exhibition. The science centre exhibition is effective only when it is well planned and structured both for content and the context of the age group. This includes support for autonomy (pupils' choices in the environment). Other implications for practical science centre pedagogy are that demonstrations and exhibits should be easily repeated to show and provide evidence and facts to prevent speculation and uncertainty. The main recommendation based on the results of this study is that the success of the science centres as informal, open environments is their potential to encourage learners to utilise deep learning strategies created by intrinsic motivation.

Open Access This article is distributed under the terms of the Creative Commons Attribution 4.0 International License (http://creativecommons.org/licenses/by/4.0/), which permits unrestricted use, distribution, 
and reproduction in any medium, provided you give appropriate credit to the original author(s) and the source, provide a link to the Creative Commons license, and indicate if changes were made.

\section{References}

Adey, P., Csapó, B., Demetriou, A., Hautamäki, J., \& Shayer, M. (2007). Can we be intelligent about intelligence? Why education needs the concept of plastic general ability. Educational Research Review, 2, 75-97. https://doi.org/10.1016/j.edurev.2007.05.001.

Adey, P., \& Shayer, M. (2002). Cognitive Acceleration comes of age. In M. Shayer \& P. Adey (Eds.), Learning intelligence: Cognitive Acceleration across the curriculum from 5 to 15 years (pp. 1-17). Buckingham: Open University Press.

Ainley, M., Hidi, S., \& Berndorff, D. (2002a). Interest, learning, and the psychological processes that mediate their relationship. Journal of Educational Psychology, 94(3), 545-561. https://doi. org/10.1037/0022-0663.94.3.545.

Ainley, M., Hillman, K., \& Hidi, S. (2002b). Gender and interest processes in response to literary texts: Situational and individual interest. Learning and Instruction, 12, 411-428. https://doi.org/10.1016/S0959 $-4752(01) 00008-1$.

Alberts, B. (2009). Making a science of education. Science, 323(5910), 15. https://doi.org/10.1126/scien ce. 1169941.

Andre, L., Durksen, T., \& Volman, M. (2017). Museums as avenues of learning for children: A decade of research. Learning Environments Research, 20(1), 47-76.

Atkinson, J. (1964). An introduction to motivation. Princeton, NJ: Van Nostrand.

Balling, J. D., \& Falk, J. H. (1981). A perspective on field trips: Environmental effects on learning. Curator, 23(4), 229-240.

Bender, W. N., \& Wall, M. E. (1994). Social-emotional development of students with learning disabilities. Learning Disability Quarterly, 17, 323-341.

Benita, M., Roth, G., \& Deci, E. L. (2014). When are mastery goals more adaptive? It depends on experiences of autonomy support and autonomy. Journal of Educational Psychology, 106(1), 258-267. https ://doi.org/10.1037/a0034007.

Bitgood, S. (1988). A comparison of formal and informal learning. Technical report 88-10. Jacksonville, AL: Center for Social Design.

Bollen, K., \& Stine, R. (1992). Bootstrapping goodness-of-fit measures in structural equation models. Sociological Methods and Research, 21, 205-229.

Braund, M., \& Reiss, M. (2004). Learning science outside the classroom. London: Routledge.

Braund, M., \& Reiss, M. (2007). What does out-of-school learning offer school science? The Science Education Review, 6, 35-37.

Byrne, B. (2010). Structural equation modeling with AMOS: Basic concepts, applications, and programming (2nd ed.). New York: Routledge.

Cohen, J. (1988). Statistical power analysis for the behavioral sciences (2nd ed.). Hillsdale, NJ: Erlbaum.

Corno, L. (2004). Introduction to the special issue work habits and work styles: Volition in education. Teachers College Record, 106(9), 1669-1694.

Corona, F., Cozzarelli, C., Palumbo, C., \& Sibilio, M. (2013). Information technology and edutainment: Education and entertainment in the age of interactivity. International Journal of Digital Literacy and Digital Competence, 4(1), 131-149. https://doi.org/10.4018/jdldc.2013010102.

Deci, E., \& Ryan, R. (2000). The "what" and "why” of goal pursuits: Human needs and the self-determination of behavior. Psychological Inquiry, 11, 227-268.

Deci, E., \& Ryan, R. (2007). Lecture in the third self-determination conference, 25th May, University of Toronto.

Deci, E., Ryan, R., \& Williams, G. (1996). Need satisfaction and the self-regulation of learning. Learning and Individual Differences, 8, 165-183.

Demetriou, A., Spanoudis, G., \& Mouyi, A. (2011). Educating the developing mind: Towards an overarching paradigm. Educational Psychology Review, 23(4), 601-663. https://doi.org/10.1007/s1064 8-011-9178-3.

Dewey, J. (1938). Experience \& education (The Kappa Delta Philecture series, Reprint 1965). New York: Collier Books.

Doppelt, Y. (2004). Impact of science-technology learning environment characteristics on learning outcomes: Pupils' perceptions and gender differences. Learning Environment Research, 7(3), 271-293. https://doi.org/10.1007/s10984-004-3297-4. 
Duschl, R., Schweingruber, H., \& Shouse, A. (Eds.). (2007). Taking science to school: Learning and teaching in grades $K-8$. Washington, DC: National Academic Press.

Eccles, J., \& Wigfield, A. (2002). Self-regulation beliefs, values, and goals. Annual Review of Psychology, $53,109-132$.

Eisenman, L. (2007). Self-determination interventions. Building a foundation for school completion. Remedial and Special Education, 28(1), 2-8. https://doi.org/10.1177/07419325070280010101.

Elliot, A. J., McGregor, H. A., \& Thrash, T. M. (2002). The need for competence. In E. L. Deci \& R. M. Ryan (Eds.), Handbook of Self-Determination Research (pp. 361-387). Rochester, New York: University of Rochester Press.

Falk, J., \& Dierking, L. (2002). Lessons without limit. Walnut Creek, CA: AltaMira.

Farenga, S., \& Joyce, B. (1999). Intentions of young students to enroll in science courses in the future: An examination of gender differences. Science Education, 83, 55-76.

Faure, E., Herrera, F., Kaddoura, A.-R., Lopes, H., Petrovsky, A. V., Rahnema, M., et al. (1972). Learning to be: The world of education today and tomorrow. Paris: UNESCO.

Fenichel, M., \& Schweingruber, H. (2010). Surrounded by science: Learning science in informal environments. Washington, DC: The National Academic Press, Board of Science Education, Center of Education, Division of Behavioral and Social Sciences and Education.

Fisher, D. (2005). Action inquiry and performance appraisals: Tools for organizational learning and development. The Learning Organization, 12(1), 26-41. https://doi.org/10.1108/09696470510574241.

Greenfield, P. (2009). Technology and informal education: What is taught, what is learned. Science, 323, 69-71. https://doi.org/10.1126/science.1167190.

Grolnick, W., \& Ryan, R. (1989). Parent styles associated with children's self-regulation and competence in school. Journal of educational Psychology, 81, 143-154.

Grolnick, W., Ryan, R., \& Deci, E. (1991). The inner resources for school achievement: Motivational mediators of children's perceptions of their parents. Journal of Educational Psychology, 83, 508-517.

Hagger, M., Sultan, S., Hardcastle, S., Reeve, J., Patall, E., Fraser, B., et al. (2016). Applying the integrated trans-contextual model to mathematics activities in the classroom and homework behaviour and attainment. Learning and Individual Differences, 45, 166-175. https://doi.org/10.1016/j.lindif.2015.11.017.

Hardre, P., \& Reeve, J. (2003). A motivational model of rural students' intentions to persist in, versus drop out of, high school. Journal of Educational Psychology, 92, 347-356. https://doi. org/10.1037/0022-0663.95.2.347.

Harris, P. (2002). Delving into Uncle Albert's cabinet: further thoughts on the pretence-reality distinction. Developmental Science, 5(4), 419-421. https://doi.org/10.1111/1467-7687.00236_5.

Hautamäki, J., Arinen, P., Eronen, S., Hautamäki, A., Kupiainen, S., Lindblom, B., et al. (2002). Assessing learning-to-learn: A framework. Helsinki: Helsinki University Printing House.

Hein, H. (1990). The exploratorium: The museum as laboratory. Washington, DC: The Smithsonian Instituion.

Hofstein, A., \& Rosenfeld, S. (1996). Bridging the gap between formal and informal science learning. Studies in Science Education, 28(2), 87-112.

Holmes, J. (2011). Informal learning: Student achievement and motivation in science through museumbased learning. Learning Environments Research, 14(3), 263-277. https://doi.org/10.1007/s1098 4-011-9094-y.

Hong, Z. (2010). Effects of collaborative science intervention on high achieving students' learning anxiety and attitudes toward science. International Journal of Science Education, 32(15), 1971-1988.

Jalil, P., Abu Sbeih, M., Boujetiff, M., \& Barakat, R. (2009). Autonomy in science education: A practical approach in attitude shifting towards science learning. Journal of Science Education and Technology, 18, 476-486. http://www.jstor.org/stable/20627730. Accessed 16 Mar 2018.

Jidesjö, A. (2008). Different content orientations in science and technology among primary and secondary boys and girls in Sweden: Implications for the transition from primary to secondary school? NorDiNa, $4(2), 192-208$.

Jidesjö, A. (2012). En problematisering av ungdomars intresse för naturvetenskap och teknik $i$ skola och samhälle-Innehåll, medierna och utbildningens function. The Swedish National Graduate School in Science and Technology Education, FontD, Department of Social and Welfare Studies, Linköping University, Sweden.

Kaplan, A. (2008). Clarifying metacognition, self-regulation, and self-regulated learning: What's the purpose? Psychological Review, 20, 477-484. https://doi.org/10.1007/s10648-008-9087-2.

La Guardia, J., Ryan, R., Couchman, C., \& Deci, E. (2000). Within-person variation in security of attachment: A self-determination theory perspective on attachment, need fulfilment, and well-being. Journal of Personality and Social Psychology, 79(3), 367-384.

McClelland, D. (1951). Motivation and personality. New York: Harper and Row. 
Michalsky, T., Mevarech, Z., \& Haibi, L. (2009). Elementary school children reading scientific texts: Effects of metacognitive instruction. The Journal of Educational Research, 102(5), 363-374. https://doi. org/10.3200/JOER.102.5.363-376.

Miles, J., \& Shevlin, M. (2001). Applying regression and correlation: A guide for students and researchers. London: Sage.

Muijtjens, A., Mameren, H., Hoogenboom, R., Evers, J., \& van der Vleuten, C. (1999). The effect of a'don't know' option on test score: Number-right and formula scoring compared. Medical Education, 33, 267275. https://doi.org/10.1046/j.1365-2923.1999.00292.x.

National Research Council. (2007). Taking science to school: Learning and teaching science in grades K-8. Washington, DC: The National Academies Press.

Oppenheimer, F. (1968). A rationale for a science museum. Curator: The Museum Journal, 11(3), $206-209$.

Osborne, J., \& Dillon, J. (2008). Science education in Europe. London: Nuffield Foundation.

Quinn, M., Rutherford, R., Leone, P., Osher, D., \& Poiries, J. (2005). Youth with disabilities in juvenile corrections: A national survey. Exceptional Children, 71(3), 339-345. https://doi.org/10.1177/00144 0290507100308 .

Radu, J. (2014). Augmented reality in education: A meta-review and cross-media analysis. Personal and Ubiquitous Computing, 18(6), 1533-1543. https://doi.org/10.1007/s00779-013-0747-y.

Raven, J., Raven, J., \& Court, J. (2000). Section 3: Standard progressive matrices. Oxford: Elsfield Hall.

Raven, J., Raven, J. C., \& Court, J. (2003). Manual for Raven's progressive matrices and vocabulary scales. Oxford: OPP Limited.

Reeve, J. (2002). Self-determination theory applied to educational settings. In E. Deci \& M. Ryan (Eds.), Handbook of self-determination (pp. 183-203). Rochester, NY: The University of Rochester Press.

Reeve, J., \& Halusic, M. (2009). How K-12 teachers can put self-determination theory principles into practice. Theory and Research in Education, 7(2), 145-154.

Reeve, J., Ryan, R., Deci, E. L., \& Jang, H. (2008). Understanding and promoting autonomous self-regulation: A self-determination theory perspective. In D. H. Schunk \& B. J. Zimmerman (Eds.), Motivation and self-regulated learning: Theory, research, and applications (pp. 223-244). Mahwah, NJ: Lawrence Erlbaum Associates Publishers.

Rennie, L. (2014). Learning science outside of school. In N. Lederman \& S. Abell (Eds.), Handbook of research on science education (Vol. II, pp. 120-144). New York: Routledge.

Rennie, L., Feher, E., Dirking, L., \& Falk, J. (2003). Towards an agenda for advancing research on science learning in out-of-school settings. Journal of Research in Science Teaching, 40(2), 112-120. https://doi.org/10.1002/tea.10067.

Renninger, K. (2000). Individual interest and its implications for understanding intrinsic motivation. In C. Sansone \& J. Harakiewicz (Eds.), Intrinsic motivation: Controversies and new directions (pp. 373-404). San Diego, CA: Academic Press.

Renninger, K.A., \& Hidi, S. (2011). Revisiting the conceptualization, measurement, and generation of interest. Educational Psychologist, 46(3), 168-184. https://doi.org/10.1080/00461520.2011.587723.

Richardson, M., Abraham, C., \& Bond, R. (2012). Psychological correlates of university students' academic performance: A systematic review and meta-analysis. Psychological Bulletin, 138(2), 353387. https://doi.org/10.1037/a0026838.

Ryan, R., \& Connell, J. (1989). Perceived locus of causality and internalization: Examining reasons for acting in two domains. Journal of Personality and Social Psychology, 57, 749-761.

Ryan, R., \& Deci, E. (2000a). Self-determination theory and the facilitation of intrinsic motivation, social development, and well-being. American Psychologist, 55(1), 68-78.

Ryan, R., \& Deci, E. (2000b). Intrinsic and extrinsic motivations: classic definitions and new directions. Contemporary Educational Psychology, 25, 54-67. https://doi.org/10.1006/ceps.1999.1020.

Ryan, R., \& Deci, E. (2002). An overview of self-determination theory. In E. L. Deci \& R. M. Ryan (Eds.), Handbook of self-determination research (pp. 3-33). Rochester, NY: University of Rochester Press.

Salmi, H. (1993). Science centre education: Motivation and learning in informal education. Research Report 119, Helsinki, Finland: Department of Teacher Education, University of Helsinki.

Salmi, H. (2003). Science centres as learning laboratories. International Journal of Technology Management, 25(5), 460-476. https://doi.org/10.1504/IJTM.2003.003113.

Salmi, H. (2012). Augmented reality in education. In Proceedings of the 'science center to go' workshops. Athens: Ellinogermaniki Agogi. http://www.sctg.eu/materials/sctgo_proceedings_low.pdf.

Salmi, H., Helena Thuneberg, H., \& Vainikainen, M.-P. (2017). Making the invisible observable by augmented reality in informal science education context. International Journal of Science Education, Part B, 7(3), 253-268. https://doi.org/10.1080/21548455.2016.1254358. 
Salmi, H., Thuneberg, H., \& Vainikainen, M.-P. (2016). How do engineering attitudes vary by gender and motivation? Attractiveness of outreach science exhibition in four countries. European Journal of Engineering Education, 18(1), 2-22. https://doi.org/10.1080/03043797.2015.1121466.

Salmi, H., Vainikainen, M.-P., \& Thuneberg, H. (2015). Mathematical thinking skills, self-concept and learning outcomes of 12-year-olds visiting a Mathematics Science Centre Exhibition in Latvia and Sweden. Journal of Science Communication, 14(4), 1-19. https://jcom.sissa.it/sites/default/files/ documents/JCOM_1404_2015_A03.pdf. Accessed 16 Mar 2018.

Schiefele, U., Krapp, A., \& Winteler, A. (1992). Interest as a predictor of academic achievement: A meta-analysis of research. In K. Renninger, S. Hidi, \& A. Krapp (Eds.), The role of interest learning and development (pp. 183-212). Hillsdale, NJ: Erlbaum.

Selye, H. (1957). The stress of life. New York: McGraw-Hill Education.

Skinner, E., \& Edge, K. (2002). Parenting, motivation, and the development of children's coping. In L. J. Crockett (Ed.), Agency, motivation, and the life course: The Nebaska symposium on motivation (Vol. 48, pp. 77-143). Lincoln, NE: University Of Nebraska Press.

Snijders, T., \& Bosker, R. (1999). Multilevel analysis: An introduction to basic and advanced multi-level modelling. London: Sage.

Svetaz, M., Ireland, M., \& Blum, R. (2000). Adolescents with learning disabilities: Risk and protective factors associated with emotional well-being: Findings from the National longitudinal study of adolescent health. Journal of Adolescence Health, 27(5), 340-348. https://doi.org/10.1016/S1054 $-139 \mathrm{X}(00) 00170-1$.

Tan, L. W. H., \& Subramaniam, R. (2003). Science and technology centres as agents for promoting science culture in developing nations. International Journal of Technology Management, 25(5), 413426. https://doi.org/10.1504/IJTM.

Thuneberg, H., Salmi, H., \& Fenyvesi, K. (2017). Hands-on math and art exhibition promoting science attitudes and educational plans. Education Research International. https://doi. org/10.1155/2017/9132791.

Vainikainen, M.-P., Salmi, H., \& Thuneberg, H. (2015). Situational interest and learning in a science centre mathematics exhibition. Journal of Research in STEM Education, 1, 15-29.

Vennix, J., den Brok, P., \& Taconis, R. (2017). Perceptions of STEM-based outreach learning activities in secondary education. Learning Environment Research, 20(1), 21-46. https://doi.org/10.1007/s1098 4-016-9217-6.

Winters, C. A. (1997). Learning disabilities, crime, delinquency, and special education placement. Adolescence, 32(126), 451-462.

White, R. (1959). Motivation reconsidered: The concept of competence. Psychological Review, 66, 279-333.

Zimmerman, B., \& Schunk, D. (2007). Motivation: An essential dimension of self-regulated learning. In D. Schunk \& B. Zimmerman (Eds.), Motivation and self-regulated learning: Theory, research, and application (pp. 1-30). Mahwah, NJ: Lawrence Erlbaum.

Zoldasova, K., \& Prokop, P. (2006). Analysis of motivational orientations in science education. International Journal of Science and Mathematics Education, 4(4), 669-688. 